\title{
EFFECTIVENESS OF CHLOROXYLENOL AND CHLORHEXIDINE - CETRIMIDE DISINFECTANTS ON FUNGAL ISOLATES FROM CLINICALLY SUSPECTED CASES OF UNCOMPLICATED OTOMYCOSIS
}

\author{
Mannur Sharada1 ${ }^{\text {, Naik Neelesh}}{ }^{2}$, Jyothi Swaroop³ ${ }^{3}$ Shah Waseem4, Savitha Hiremath ${ }^{5}$, Nagaraj E.R 6
}

HOW TO CITE THIS ARTICLE:

Mannur Sharada, Naik Neelesh, Jyothi Swaroop, Shah Waseem, Savitha Hiremath, Nagaraj ER. "Effectiveness of chloroxylenol and chlorhexidine - cetrimide disinfectants on fungal isolates from clinically suspected cases of uncomplicated otomycosis". Journal of Evolution of Medical and Dental Sciences 2013; Vol2, Issue 34, August 26; Page: 6411-6414.

ABSTRACT: BACKGROUND: Otomycosis is a superficial mycotic infection of the external auditory canal. The infection may be either subacute or chronic in nature. Otomycosis occurs world-wide but is more common in tropical and subtropical countries. Fungal agents most commonly causing otomycosis are Aspergillus niger, Candida albicans, Aspergillus flavus, Aspergillus fumigatus, Candida parapsilosis, Penicillium, Mucor, Rhizopus, Absidia and Scopuloriopsis spp. Many agents have been recommended for treating otomycosis, but no preparation has been widely accepted. Vigorous cleaning of the external auditory canal remains the mainstay in treating otomycosis, along with usage of topical anti-fungal agents. OBJECTIVE: To compare the efficacy of chloroxylenol (Dettol) and chlorhexidine- cetrimide (savlon) with 1\% clotrimazole $+1 \%$ lidocaine ear drops. METHODS AND MATERIALS: Agar well diffusion method was used on the isolates obtained from uncomplicated clinically diagnosed otomycosis cases. RESULTS: The isolates, Aspergillus niger, Aspergillus flavus, Candida albicans, Candida glabrata and Candida parapsilosis were susceptible to undiluted concentration of dettol and not susceptible to savlon. CONCLUSION: Dettol can be used to reduce the fungal burden in the external auditory canal, and it should be followed by topical application of clotrimazole ear drops to cure the disease.

KEY WORDS: Otomycosis, Aspergillus, Candida.

INTRODUCTION: Otomycosis is a superficial, subacute or chronic mycotic infection of the external auditory canal; however the disease may occur in the middle ear if the tympanic membrane is perforated ${ }^{1-4}$. Usually unilateral and presents with symptoms like pruritis, discomfort and pain in the ear, aural fullness, tinnitus, hearing impairment and sometimes discharge. It occurs world-wide but is more common in tropical and subtropical countries ${ }^{5}$. Fungal agents most commonly causing otomycosis are Aspergillus niger, Candida albicans, Aspergillus flavus, Aspergillus fumigatus, Candida parapsilosis, Penicillium, Mucor, Rhizopus, Absidia and Scopuloriopsis spp. It is estimated that approximately $5-25 \%$ of the total cases of otitis externa are due to otomycosis 6,7 . Predisposing factors of otomycosis include chronic infections of the ear, use of oils, hearing aid, eardrops, steroids, swimming, immuno-compromised state and fungal infection elsewhere in the body like dermatomycosis and malnourishment in children ${ }^{7-10}$. Topical antiseptics and antifungal agents are frequently used for the treatment of otomycosis.

\section{AIMS AND OBJECTIVES:}

(1) To isolate and identify the fungal isolates from clinically suspected cases of otomycosis 


\section{ORIGINAL ARTICLE}

(2) To know the effectiveness of chloroxylenol and chlorhexidine- cetrimide on fungal isolates by agar well diffusion method

METHODS AND MATERIALS: In this prospective study, mycological analysis was carried out on samples collected from auditory canal of 35 patients clinically suspected of otomycosis in the outpatient department of Oto-Rhino-Laryngology (E.N.T.) between the period from September 2012 to February 2013. The patient's clinical profiles regarding age, sex, laterality, and clinical presentation were documented. Patients who were already on treatment for otomycosis were excluded from the study. Samples were collected in a sterile universal container and were immediately transported to the department of Microbiology.

Direct microscopic examination of the obtained specimens was carried out for detection of fungal elements by KOH (10\%) mount and Gram's stain. Sample was inoculated into Sabouraud's Dextrose Agar and the tubes were incubated at $25^{\circ} \mathrm{C}$ and $37^{\circ} \mathrm{C}$ for a minimum period of 4 weeks. The culture tubes were examined for the presence of growth every 3-4 days. Identification of the fungus was done by Lacto phenol Cotton Blue Mount preparation, Gram's Stain and colony morphology. Slide culture examination was used for differentiation of morphology of filamentous fungi. Biotyping of Candida species was performed using Germ tube Test, detection of Chlamydospore formation on Corn Meal Agar and Hi Chrome Candida differentiation media. The turbidity of fungal spore suspension was prepared by hemocytometric method. Lawn culture of fungal isolates was made on Sabouraud's Dextrose Agar and four wells with $6 \mathrm{~mm}$ bore were dug with the help of cork borer. 100 microlitre of disinfectants was dispensed in the dug well. After 24 hours the zone of inhibition (ZOI) was measured using ZOI measuring scale. The $1 \%$ clotrimazole $+1 \%$ lidocaine ear drops was taken as standard to which other disinfectants were compared. The normal saline was used as negative control. The standard strain used in the study was Candida albicans ATCC 22019.

RESULTS: In our study, among the otomycosis patients, 54.2\% were caused by Aspergillus niger, $13.6 \%$ by Aspergillus flavus, $2.2 \%$ by Aspergillus fumigatus, $9.0 \%$ by Candida species and $11.3 \%$ showed mixed growth of fungi. The study included patients of age group ranging from $13-70$ years. The youngest was a 13 year old male patient and the eldest was a 70 year old male patient. Maximum number of cases were between 30-39 years of age. We observed increased incidence of otomycosis among females (54.5\%) and more involvement of left ear. The predominant complaints were fullness of ear and itching, followed by earache, ear discharge and tinnitus. (Table no 1) Clinical examination revealed canal skin erythema and fungus debris in all cases. $60.8 \%$ of the patients gave history of water entry into the external auditory canal and $45.9 \%$ of the patients gave history of use of unsterile material - oil, swabs, and sticks. (Table no 2) The ZOI for $1 \%$ clotrimazole+1\% lidocaine ear drops against the Aspergillus species and Candida species was in the range between $36-38 \mathrm{~mm}$ and the ZOI for chloroxylenol was in the range between $54-56 \mathrm{~mm}$ which was above the ZOI of the standard. Chlorhexidine- cetrimide was ineffective and showed ZOI of $16-18 \mathrm{~mm}$.

Table: 1. Clinical presentation of mycotic otitis externa

\begin{tabular}{|c|c|}
\hline Symptoms & Percentages (\%) \\
\hline Itching & 66.4 \\
\hline Pain & 60.2 \\
\hline
\end{tabular}




\section{ORIGINAL ARTICLE}

\begin{tabular}{|c|c|}
\hline Fullness of ear & 82.9 \\
\hline Discharge & 18.9 \\
\hline Tinnitus & 0.5 \\
\hline Others & 0.5 \\
\hline
\end{tabular}

Table: 2. Predisposing factors for mycotic otitis externa

\begin{tabular}{|l|c|}
\hline \multicolumn{1}{|c|}{ Predisposing Factors } & Percentage (\%) \\
\hline Chronic Suppurative Otitis Media & 27 \\
\hline Use of ear drops & 21.6 \\
\hline Use of head cloths & 27 \\
\hline Water entry into the ear & 60.8 \\
\hline Use of unsterile material - oil, swabs, sticks & 45.9 \\
\hline Previous surgeries & 9.4 \\
\hline Others & 4.05 \\
\hline
\end{tabular}

DISCUSSION: The most common fungus isolated from cases of otomycosis in our study was Aspergillus niger which was also the most common isolate reported in other studies 11, 12. To our knowledge, this is the first report in the English literature investigating the in vitro efficacy of chloroxylenol and chlorhexidine- cetrimide disinfectants on Aspergillus species, C. albicans and C. glabrata isolated from the ears with otomycosis. We employed the agar well diffusion method as described by Senthil Kumar and M Kamaraj ${ }^{13}$. We concluded that chloroxylenol has a strong activity against all the fungal isolates from otomycosis and hence can be used for aural cleaning before using the antifungal agents. The study being an in-vitro study and the sample size being small were the limitations of the study. We further recommend in-vivo study of usefulness of these disinfectants for aural toileting and to reduce the fungal burden in cases of otomycosis.

\section{REFERENCES}

1. Chalabi YE, San -Ahmed ST. The role of various out patient's aural toileting procedures in the treatment of otomycosis. Journal of Zankoy Sulaimani 2010; 13(1):39-48.

2. Aneja KR, Sharma C, Joshi R. Fungal infection in the ear; A common problem in the north eastern part of Haryana. Int J Paediatr Otorhinolaryngol 2010; 74:604-7.

3. Fasunla J, Lbekwetank OP. Otomycosis in western Nigeria. Mycoses 2008; 51:67-70.

4. Vrabec JT, Yoo D, Coker NJ. Otomycosis: clinical features and treatment implications. Otolaryngology Head Neck surgery 2006; 135:787-91.

5. Satish HS, Vishwanatha B, Manjuladevi M. A clinical study of otomycosis. JDMS 2013; 5(2):57-62.

6. Munguia R, Daniel SJ. Oto topical antifungals and otomycosis: a review. Int J Pediatr Otorhinolaryngol 2008; 72:453-9.

7. Gokale SK, Suligavi SS, Baragundi M, Anushka D, Manjula R. Otomycosis: A clinico mycological study. Int J Med Health Sci 2013; 2(2):218-23. 


\section{ORIGINAL ARTICLE}

8. Pradhan B, Tuladhar NR, Amatya RM. Prevalence of otomycosis in outpatient dept of otolaryngology in Tribhuvan University teaching hospital, Kathmandu, Nepal. Ann Otol Rhinol Laryngol 2003; 112:384-7.

9. Zelia BV, Anna DF, Edeltrudes OL, Marcio HG, Neuza MCO, Maria FF, Felipe SQG. Otomycosis: a retrospective study. Braz J Otorhinolaryngol 2009; 75(3):367-70.

10. Guiterrez PH, Alvavez SJ, Sanudo EC, Sanchez CR, Valdezate I, Garcia LMG. Presumed diagnosis- Otomycosis: A study of 451 patients. Acta Otorhinolaryngol Esp 2005; 56:181-6.

11. Kumar A. Fungal spectrum in otomycosis patients. JK science 2005; 7(3):152-5.

12. Sarvan RR, Kikani KM, Mehta SJ, Joshi PJ. Clinico- mycological study of otomycosis. Int J Biol Med Res 2012; 3(4):2469-70.

13. Kumar SS, Kamaraj M. Antimicrobial activity of Cucumis anguria by agar well diffusion method. Botany Research Investigational 2011; 4(2):41-2.

\section{AUTHORS:}

1. Mannur Sharada

2. Naik Neelesh

3. Jyothi Swaroop

4. Shah Waseem

5. Savitha Hiremath

6. Nagaraj E.R.

\section{PARTICULARS OF CONTRIBUTORS:}

1. Associate Professor, Department of ENT, Sri Siddhartha Medical College and Research Centre.

2. Assistant Professor, Department of Microbiology, Sri Siddhartha Medical College and Research Centre.

3. Associate Professor, Department of ENT, Sri Siddhartha Medical College and Research Centre.

4. Post Graduate, Department of ENT, Sri Siddhartha Medical College and Research Centre.
5. Post Graduate, Department of Microbiology, Sri Siddhartha Medical College and Research Centre.

6. Professor and HOD, Department of Microbiology, Sri Siddhartha Medical College and Research Centre.

\section{NAME ADDRESS EMAIL ID OF THE CORRESPONDING AUTHOR:}

Dr. Sharadadevi Mannur Y, Department of Microbiology, Sri Siddhartha Medical College, Tumkur, Karnataka - 572107.

Email-drysdm71@yahoo.co.in

Date of Submission: 14/08/2013. Date of Peer Review: 16/08/2013. Date of Acceptance: 19/08/2013. Date of Publishing: 21/08/2013 